Check for updates

Cite this: RSC Adv., 2018, 8, 190

Received 22nd November 2017 Accepted 13th December 2017

DOI: $10.1039 / c 7 r a 12688 c$

rsc.li/rsc-advances

\section{An unexpected re-arrangement of the antibiotic carbapenem core to new 1,4-diazepin-5-one scaffolds $\uparrow$}

\author{
Byron K. Peters, ${ }^{a}$ Rufaro Razuwika, ${ }^{a}$ Marivel Samipillai, ${ }^{a}$ Per I. Arvidsson, (D) ab \\ Hendrik G. Kruger, (D) ${ }^{a}$ Thavendran Govender ${ }^{\star a}$ and Tricia Naicker (D) *a
}

\begin{abstract}
Herein we report a peculiar organocatalyzed domino-reaction on the carbapenem core structure. As previously reported, $30 \mathrm{~mol} \%$ of proline yields diazabicyclo[4.2.1]nonane analogues, while we currently report the formation of novel 1,4-diazepin-5-ones from the same starting material in the presence of $100 \mathrm{~mol} \%$ proline. The inherent chirality of the starting material led to the stereochemical preference of the products with excellent diastereoselectivity $(>99: 1)$ ). The diazepinone products were confirmed using X-ray diffraction and 2D-NMR structure elucidation. A plausible mechanism of the re-arrangement, involving an unactivated retro-Dieckmann condensation, is also presented.
\end{abstract}

Diazepinone analogues have become essential scaffolds due to their pharmacological properties and peptidomimetic functions. ${ }^{1-3}$ Preparation of these derivatives are currently gaining momentum in modern day organic synthesis with focus on the discovery and optimization of bioactive compounds. ${ }^{4-6}$ There has been an increase in fragment-based drug discovery and lead optimization which focuses on the fragments' structural shape or complexity. ${ }^{7,8}$ Fragments of a drug containing a saturated core, with $\mathrm{sp}^{3}$ carbon atoms, are commonly considered to have a 3D character (protruding diffusely in all directions), as opposed to planar aromatic rings (flat and protruding mainly in two planes). Chan and co-worker's review article exemplifies that utilizing more 3D character in drug design would increase the diversity of fragment screening libraries, improve ADMET properties, and provide better starting points for lead generation as well as possibly address 'difficult' targets. 'Therefore, moving towards $\mathrm{sp}^{3}$-rather than $\mathrm{sp}^{2}$-character drug scaffolds is now a major focus in the organic/medicinal chemistry community. ${ }^{\mathbf{1 0 , 1 1}}$ Diazepinone containing molecules, aside from being rigid and readily tuneable, possess a high degree of 3D structure. Therefore, the development of catalytic methods for their preparation will be beneficial for expanding the scope of fused heterocycles.

${ }^{a}$ Catalysis and Peptide Research Unit, University of KwaZulu Natal, Durban, South Africa, 4001. E-mail: govenderthav@ukzn.ac.za; naickert1@ukzn.ac.za

${ }^{b}$ Science for Life Laboratory, Drug Discovery \& Development Platform, Division of Translational Medicine and Chemical Biology, Department of Medical Biochemistry and Biophysics, Karolinska Institutet, Stockholm, Sweden

$\dagger$ Electronic supplementary information (ESI) available. CCDC 1455806. For ESI and crystallographic data in CIF or other electronic format see DOI: $10.1039 / \mathrm{c} 7 \mathrm{ra} 12688 \mathrm{c}$
Our group has recently reported several organocatalyzed transformations on the bicyclic carbapenem core as a route to unexplored $\beta$-lactam derivatives. ${ }^{12-15}$ The carbapenem-based drugs have a wide range of activities and also the greatest potencies against Gram positive and negative bacteria. ${ }^{16-20}$ The high reactivity of $\beta$-lactams makes them an important class of compounds in organic synthesis as chiral building blocks for molecules of potential pharmaceutical importance. ${ }^{21,22}$ Our findings on the Mannich reaction on the carbapenem core has led to some interesting and unexpected products (Scheme 1, A and B). ${ }^{13}$ Previously, we reported the 2 - and 3 -component Mannich reactions respectively; the diazabicyclo[4.2.1]nonane formed from reaction $\mathbf{B}$ was explained by an intramolecular nucleophilic cyclization re-arrangement due to its close proximity to the lactam ring. ${ }^{13}$ Herein we report an entirely different re-arrangement induced by increasing the amount of proline used, wherein a new class of fused diazepinones (C) are formed from 1.

\section{Results and discussion}

As an extension of our previous work, ${ }^{13}$ the PNB protected carbapenem was smoothly converted into diazabicyclo[4.2.1]nonane derivatives (via the enamine intermediate), bearing a variety of groups (Scheme 2). Phenyl, methyl, and COOMe were all tolerated and the products furnished in good yields. Moreover, crude imines generated from the reaction of paraformaldehyde and the corresponding amine in the presence of anhydrous $\mathrm{MgSO}_{4}$ could be used without any negative impact on the yield of 2. Diastereomeric ratios were $>99: 1$ from the crude ${ }^{1} \mathrm{H}$ NMR spectrum. This was attributed to the inherent chirality on the carbapenem scaffold. ${ }^{14}$ 

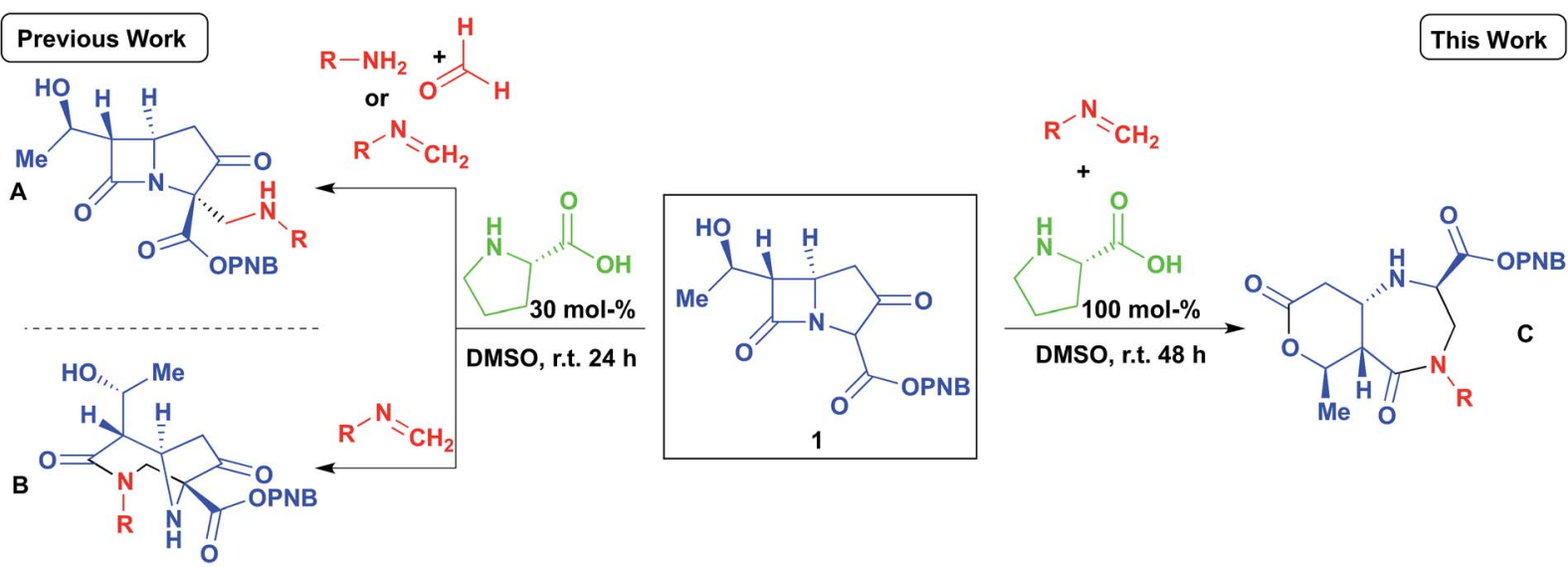

$A, R=$ Aryl $B$ and $C, R=$ Alkyl

Scheme 1 The organocatalyzed transformations of $p$-nitrobenzyl-6-(1-hydroxyethyl)-1-azabicyclo(3.2.0)heptane-3,7-dione-2-carboxylate (carbapenem), by 3 -component Mannich reaction (reaction A) and by 2-component Mannich reactions to bicyclic diazanonane (reaction $\mathrm{B}$ ) and to 1,4-diazepin-5-one (reaction C) respectively.

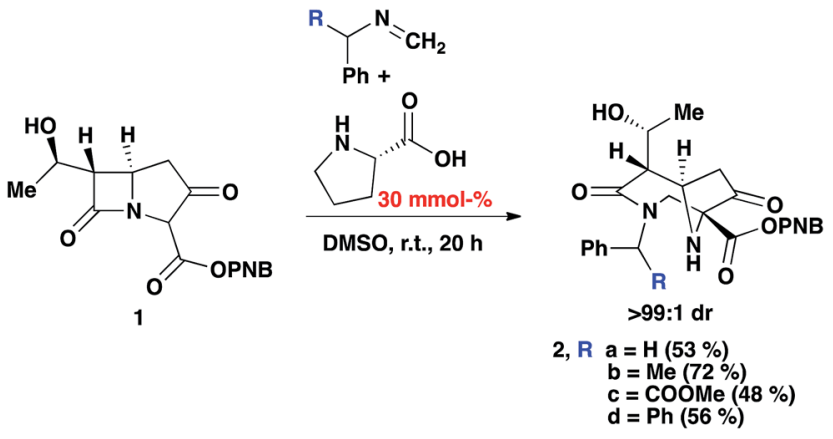

Scheme 2 2-Component Mannich reaction of an imine and carbapenem, with $30 \% \mathrm{mmol}(S)$-proline in DMSO.

The reaction was subjected to an increased amount of proline while maintaining the same concentration of carbapenem. Unexpectedly, at $100 \mathrm{~mol} \%$ proline it was observed that after 48-72 hours, an entirely new product was formed (Scheme 3). The differences in the transformation of the carbapenem-based products were detected in the ${ }^{1} \mathrm{H}$ NMR, LCMS retention time and by analysis of a single crystal with X-ray diffraction (vide infra). These analyses revealed that a new

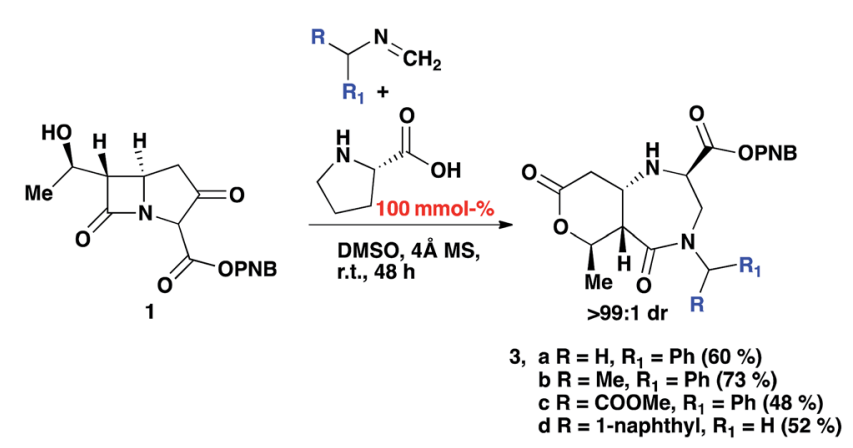

Scheme 3 2-Component Mannich reaction of an imine and carbapenem, with $100 \% \mathrm{mmol}(S)$-proline and $4 \AA$ MS in DMSO. heterocyclic type structure had formed (3). Expanding the scope of the reaction further produced diazepinones for both $\mathrm{R}=\mathrm{Me}$ and COOMe (3b and 3c). Even with a bulky 1-naphthyl group the product was formed smoothly in 72 hours in good yield (3d). Addition of $200 \mathrm{~mol} \%$ proline or even a larger excess brought about the same result. Reducing the amount of proline to $30 \%$ generated a product mixture after 48 hours, with characteristic signals for both 2 and 3 being detected at a ratio of $61: 38$ in the crude ${ }^{1} \mathrm{H}$ NMR spectrum. Upon isolation of product $\mathbf{2 b}$ followed by subjection to the aforementioned reaction conditions with an excess of proline after 24 hours resulted in the formation of product $\mathbf{3 b}$, confirming that $\mathbf{2 b}$ is a necessary intermediate to 3b. A linear type relationship was observed for the formation of 3b over a 12-48 hour period with increasing amounts of proline. For time studies using fixed amounts of proline, a steady state was observed after 12 hours, indicating that the formation of product $\mathbf{3 b}$ is strongly dependent on the amount of proline that is present.

Diazepinone heterocycles are frequently encountered in natural products and pharmaceutically active molecules. ${ }^{1,23-25}$ Studies have also shown that their biological activities can be heightened when fused with aromatic rings. Therefore, these products boast high value to the pharmaceutical industry as

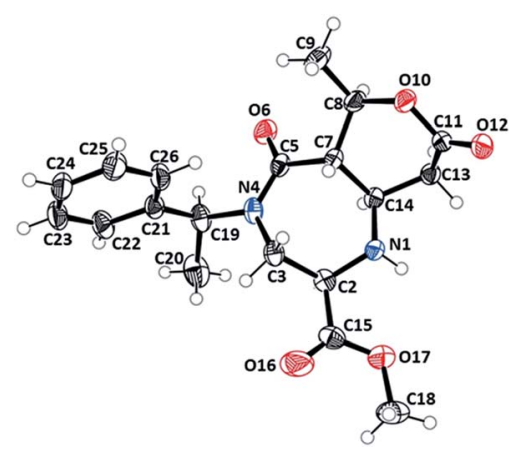

Fig. 1 X-ray crystal structure (ORTEP) of $3 b$ analogue. ${ }^{26}$ 


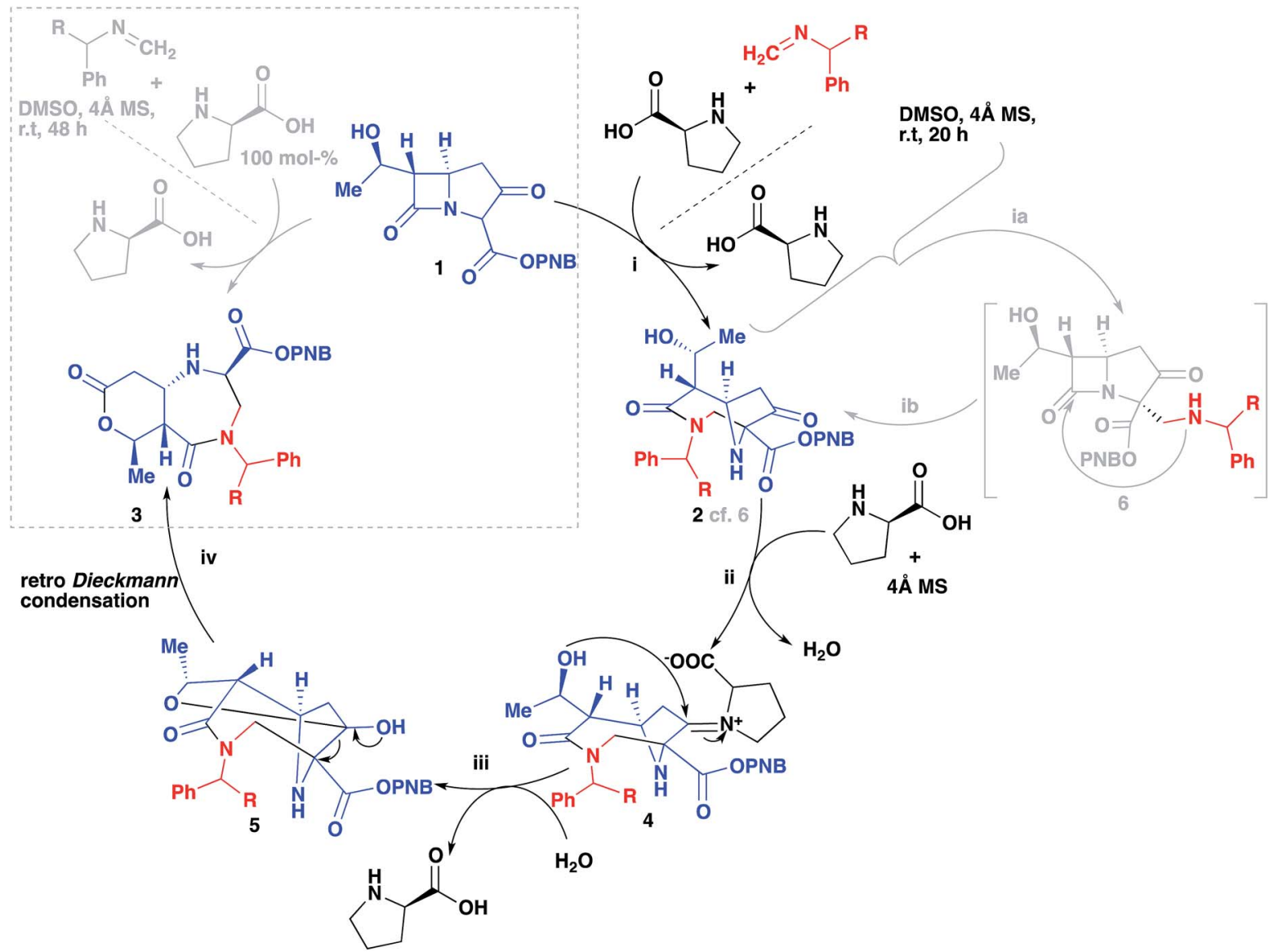

Scheme 4 The proposed re-arrangement mechanism of $3 a-d$ in the presence of excess (S)-proline.

novel core structures for drug candidates and as synthetic intermediates. The stereocenters of the rearranged products were assigned to be $(R) \mathrm{C}_{2},(S) \mathrm{C}_{7},(R) \mathrm{C}_{8}$ and $(S) \mathrm{C}_{14}$ based on the Xray structure of $3 \mathbf{b}$ (Fig. 1). ${ }^{26}$ The absolute configuration of the other products were assigned by the analogy. The six membered tetrahydro- $2 \mathrm{H}$-pyran-2-one ring of undec-6,10-dione appeared in a twisted boat conformation while the seven membered diazepane ring is in a chair conformation.

In Scheme 4 we propose a mechanism to rationalize the origins of this useful re-arrangement. First 2 is formed as suggested previously $(\mathbf{i}, \mathbf{2})^{13}$ via an intermediate (ib, 6), then an excess of proline participates in the formation of an iminium intermediate (ii, 4). This highly electrophilic species can then undergo an intermolecular nucleophilic attack from the alcohol (iii, 5). Hydration to regenerate the proline followed by a retroDieckmann generates the diazepinone scaffold (iv, 3 ).

\section{Conclusions}

This methodology demonstrated that an organocatalyzed Mannich reaction could alter the reactivity of the carbapenem core into a series of novel diazepinone compounds. High diastereoselectivities were observed in all of the reaction products (>99:1). The structure of the fused diazepinone scaffold was also supported by a single X-ray crystal structure as well as full
2D NMR elucidation (see ESI†). In both cases, multiple bond formation takes place in one-pot, an otherwise rare and challenging synthetic operation. To our knowledge this is the first time that such a re-arrangement has been observed by any $\beta$ lactam analogue. The new highly functionalised scaffolds can be further transformed to allow for the preparation of unexplored fused diazepinone libraries containing 7 or 8-membered heterocyclic rings that could be used to address the everincreasing intricacy of biological targets/systems from various diseases.

\section{Conflicts of interest}

There are no conflicts to declare.

\section{Acknowledgements}

The authors thank the National Research Foundation (South Africa), the University of KwaZulu Natal and Aspen Pharmacare for financial support.

\section{Notes and references}

1 A. A. Dörr and W. D. Lubell, Org. Lett., 2015, 17, 3592-3595. 
2 C. G. Joseph, K. R. Wilson, M. S. Wood, N. B. Sorenson, D. V. Phan, Z. Xiang, R. M. Witek and C. Haskell-Luevano, J. Med. Chem., 2008, 51, 1423-1431.

3 K. Upadhyay, A. Manvar, K. Rawal, S. Joshi, J. Trivedi, R. Chaniyara and A. Shah, Chem. Biol. Drug Des., 2012, 80, 1003-1008.

4 A. A. Fesenko, M. S. Grigoriev and A. D. Shutalev, J. Org. Chem., 2017, 82, 8085-8110.

5 M. Viviano, C. Milite, D. Rescigno, S. Castellano and G. Sbardella, RSC Adv., 2015, 5, 1268-1273.

6 R. Costil, Q. Lefebvre and J. Clayden, Angew. Chem., Int. Ed., 2017, 56, 14602-14606.

7 C. W. Murray, M. L. Verdonk and D. C. Rees, Trends Pharmacol. Sci., 2012, 33, 224-232.

8 A. W. Hung, A. Ramek, Y. Wang, T. Kaya, J. A. Wilson, P. A. Clemons and D. W. Young, Proc. Natl. Acad. Sci. U. S. A., 2011, 108, 6799-6804.

9 M. Aldeghi, S. Malhotra, D. L. Selwood and A. W. E. Chan, Chem. Biol. Drug Des., 2014, 83, 450-461.

10 O. E. Jerry and Z. Weifan, Curr. Top. Med. Chem., 2010, 10, 669-679.

11 F. Lovering, J. Bikker and C. Humblet, J. Med. Chem., 2009, 52, 6752-6756.

12 Z. E. D. Cele, P. I. Arvidsson, H. G. Kruger, T. Govender and T. Naicker, Eur. J. Org. Chem., 2015, 2015, 638-646.

13 Z. E. D. Cele, S. A. Pawar, T. Naicker, G. E. M. Maguire, P. I. Arvidsson, H. G. Kruger and T. Govender, Eur. J. Org. Chem., 2014, 2014, 2253-2260.

14 S. A. Pawar, S. Alapour, S. Khanyase, Z. E. D. Cele, S. Chitti, H. G. Kruger, T. Govender and P. I. Arvidsson, Org. Biomol. Chem., 2013, 11, 8294-8297.
15 S. Khanyase, T. Naicker, G. E. M. Maguire, H. G. Kruger, P. I. Arvidsson and T. Govender, Tetrahedron: Asymmetry, 2014, 25, 969-973.

16 A. Batirel, I. Balkan, O. Karabay, C. Agalar, S. Akalin, O. Alici, E. Alp, F. Altay, N. Altin and F. Arslan, Eur. J. Clin. Microbiol. Infect. Dis., 2014, 33, 1311-1322.

17 J. S. Bradley, J. Garau, H. Lode, K. V. I. Rolston, S. E. Wilson and J. P. Quinn, Int. J. Antimicrob. Agents, 1999, 11, 93-100.

18 N. Heinrich, R. Dawson, J. du Bois, K. Narunsky, G. Horwith, A. J. Phipps, C. A. Nacy, R. E. Aarnoutse, M. J. Boeree, S. H. Gillespie, A. Venter, S. Henne, A. Rachow, P. P. J. Phillips, M. Hoelscher and A. H. Diacon, J. Antimicrob. Chemother., 2015, 70(5), 1558-1566.

19 A. C. Rodloff, E. J. C. Goldstein and A. Torres, J. Antimicrob. Chemother., 2006, 58, 916-929.

20 P. M. Shah and R. D. Isaacs, J. Antimicrob. Chemother., 2003, 52, 538-542.

21 C. T. Brain, A. Chen, A. Nelson, N. Tanikkul and E. J. Thomas, Tetrahedron Lett., 2001, 42, 1247-1250.

22 A. Chen, A. Nelson, N. Tanikkul and E. J. Thomas, Tetrahedron Lett., 2001, 42, 1251-1254.

23 G. I. Yranzo and E. L. Moyano, in Comprehensive Heterocyclic Chemistry III, ed. C. A. Ramsden, E. F. V. Scriven and R. J. K. Taylor, Elsevier, Oxford, 2008, pp. 399-431, DOI: 10.1016/ B978-008044992-0.01214-1.

24 D. Y. Wang, M. I. Abboud, M. S. Markoulides, J. Brem and C. J. Schofield, Future Med. Chem., 2016, 8, 1063-1084.

25 O. Monasson, M. Ginisty, J. Mravljak, G. Bertho, C. GravierPelletier and Y. Le Merrer, Tetrahedron: Asymmetry, 2009, 20, 2320-2330.

26 See ESI $\dagger$ for details. CCDC 1455806 contains the supplementary crystallographic data for this paper. 